\title{
Chapter 5 \\ Toward Social Infrastructure: \\ Typological Idea for Evaluating \\ Implementation Potential of Green \\ Infrastructure
}

\author{
Takeshi Osawa and Takaaki Nishida
}

\begin{abstract}
Green infrastructure (GI) comprises widely distributed objects in human residential communities. However, because of the variety of certain objects, it is sometimes difficult to improve public awareness and enhance social implementation of GI. To expand the idea of GI and apply it widely in our society, we should understand clearly what exactly GI is and where and how it can be applied. In this article, we classify the types of GI and present a basic approach to evaluate their implementation potential as the first step for expanding the application of GI in human society. First, based on the definition of GI, we classified it as the infrastructure involving the natural ecosystem, seminatural ecosystem, and artificial ecosystem in each. The essential differences among these types arise from their installability depending on human activities. Then, we considered the principle of evaluation of the implementation potential of GI for the three types GI based on three dimensions, natural condition, top-down regulation, and bottomup regulation, in human society. Additionally, appropriate ideas for the evaluation of each dimension were considered. Relative importance of the natural condition, top-down regulation, and bottom-up regulation differs among the types of GI. We believe that the findings of this work will be useful for decision makers dealing with the application of GI in their administrative areas.
\end{abstract}

Keywords Artificial ecosystem - Decision support - Driving force pressure state impact response (DPSIR) framework · Installability $\cdot$ Seminatural ecosystem

T. Osawa (ه)

Graduate School of Urban Environmental Sciences, Tokyo Metropolitan University, Tokyo, Japan

T. Nishida

Kyoto Sangyo University, Kyoto, Japan

Mitsubishi UFJ Research and Consulting Co. Ltd., Osaka, Japan

(C) The Author(s) 2022

F. Nakamura (ed.), Green Infrastructure and Climate Change Adaptation,

Ecological Research Monographs, https://doi.org/10.1007/978-981-16-6791-6_5 


\subsection{Introduction}

Green infrastructure (GI) is defined as the natural, seminatural, and artificial networks of multifunctional ecological systems within, around, and between human residential communities on all spatial scales (Tzoulas et al. 2007; Pearlmutter et al. 2017). This concept can cover a wide range of elements such as intact forests (Svensson et al. 2019), wetland (Nakamura et al. 2019), agricultural land (Osawa et al. 2020a), and urbanized green spaces (Tzoulas et al. 2007; Matsunaga and Osawa 2021). Thus, GI can exist widely in human residential communities. However, such a broad definition sometimes makes it difficult for decision makers, such as government personnel who are the stakeholders for the development of infrastructures, to perceive GI. For example, a policy maker who is responsible for the mitigation of climate change tends to focus on the GI that is useful for carbon fixation (e.g., Chen 2015). Health-care professionals, such as public health department personnel and hospital operators, tend to focus on the GI that can benefit the human health, both physical and mental (e.g., Tzoulas et al. 2007). Although many categories of people have a potential interest in GI, integrating their interests to link various GI implementation practices is a challenge. In addition, local residents often cannot perceive the existing GI itself, i.e., the ecosystem with ecosystem services existing around them (Zhang et al. 2010; Cortinovis and Geneletti 2018). These challenges hamper the application of GI as social infrastructure for the human society. To expand the idea and application of GI and to contribute the human society, a clear understanding of what GI comprises and where and how it can be applied is necessary.

Proposing a typology for conceptual term is one of the effective ways to perceive future challenges for research and management (Eggermont et al. 2015). Thus, we can consider that clarifying and classifying the concept of GI are important steps to discuss the feasibility of the application of GI as social infrastructure. In this work, we expanded the basic concept of GI to evaluate its implementation potential for the human society and to improve its applicability as social infrastructure, especially for land managers and decision makers. First, based on the basic definition of GI and the concept of human society-environment interactions, we classified the GI for three types of ecosystems, i.e., the natural, seminatural, and artificial ecosystems. Second, we proposed the underlying concept of the components of GI implementation potential for GI and considered basic methods to evaluate it. Finally, we discussed the next challenges and perspectives for the application of GI.

\subsection{Classification Basis for GIs}

One of the challenges in expanding the idea and implementing GI in the human society is to link with concept of that already widely accepted in other fields (Romano et al. 2015; Spanò et al. 2017). Spanò et al. (2017) indicated the use- 
fulness of the driving force-pressure-state-impact-response (DPSIR) framework to integrate knowledge between diverse disciplines and GI (Svarstad et al. 2008). This framework considers the driving forces (D) (e.g., human activity) that exert pressure (P) (e.g., land-use change), leading to changes in the state (S) (e.g., ecological processes) and thereby cause impacts (I) and the human health and society that may elicit a societal response (R) (Spanò et al. 2017). At the heart of this framework is a simple incorporation of the interaction between human society and environment. The GI should support the human society, and thus, GI should interact with human activities. That is, for an ecosystem to be classified as GI, humans should take appropriate efforts (driving force and pressure) to regulate that ecosystem as required by humans. Interaction between the human society and environment is an essential factor in determining the GI, and hence, this factor should be considered when classifying GI.

\subsection{Classification of GI}

Based on the conceptual definition of GI considering the interactions between the human society and environment, we can specify at least three types of elements, namely, the natural ecosystem, seminatural ecosystem, and artificial ecosystem as GI (Fig. 5.1). Examples of natural ecosystems as GI are coral reefs, which can reduce the impact of ocean waves (Martin and Watson 2016), and natural wetland, which can reduce flooding occurrences (Nakamura et al. 2019). Examples of seminatural ecosystems as GI are paddy fields, which have a variety of functions such as food production, wetland habitat support (Natuhara 2013; Osawa et al. 2020b), and disaster prevention (Osawa et al. 2020a, b). Artificial ecosystems as GI include rain gardens, which are urban green spaces that store rain water and prevent urban flooding (Ishimatsu et al. 2017). These three types have clear differences in terms of their installability depending on human activities, i.e., the driving force and pressure in the DPSIR framework (Fig. 5.1). To be specific, we cannot create a natural ecosystem, and it is difficult to create a seminatural ecosystem by ourselves; nevertheless, we can support these ecosystems and create an artificial ecosystem in any area in theory. Thus, the implementation potentials for natural and seminatural ecosystem-based GI are strongly regulated by the location of the target area, whereas there are few such limitations on GI based on artificial ecosystems-this is an important aspect related to the implementation potential of GI. Of course, it may be possible to combine these types of GI. However, for simplicity, we have classified them clearly in this work.

This classification is similar to the classification of nature-based solution $(\mathrm{NbS})$, proposed by Eggermont et al. (2015). They proposed that NbS could be applied along with two evaluation axes. Those are (1) the extent of involvement of biodiversity and ecosystems' engineering in $\mathrm{NbS}$ and (2) the number of ecosystem services and stakeholder groups that are targeted by a given $\mathrm{NbS}$. Moreover, they discussed that low level of axis 1 combined with high level of axis 2 constitutes 


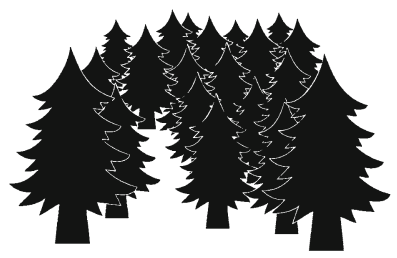

Natural ecosystem

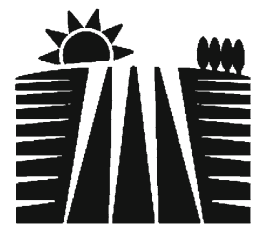

Seminatural ecosystem

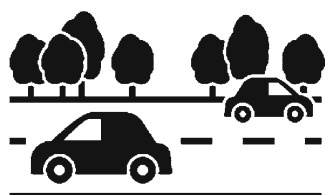

Artificial ecosystem

Installability by humans (Driving force and Pressure)

Fig. 5.1 Essential differences among the three types of green infrastructure (GI)

ecosystem with no or minimal intervention; both mid-levels are connected with human-mediated ecosystem, namely, seminatural; and high level of axis 1 combined with low level of axis 2 constitutes artificial ecosystem. Although they categorized GI as the artificial ecosystem, which comprises high level of axis 1 combined with low level of axis 2 (Eggermont et al. 2015), the basic idea established by interaction between the human society and environment is common.

\subsection{Three Dimensions for the Implementation Potential of GI}

We propose three dimensions for evaluating implementation potential of GI (Fig. 5.2). The first is natural condition. Implementation potential of natural and seminatural GI is basically regulated by their geographical setting. We cannot introduce a coral reef as GI in a mountainous or hilly area. We cannot introduce a forest as GI for the sea. Thus, implementation potential of a GI type should be defined based on the geographical setting, i.e., the natural condition in the target area. This is one of essential dimensions for evaluating the implementation potential of GI.

Second is top-down regulation (Fig. 5.2). Artificial ecosystem such as urban green spaces can be created by humans. In other words, the implementation potential of this type of GI is not as strongly regulated by the geographical setting as in the case of the other two types. That is, in theory, artificial GI can be introduced anywhere. However, such GIs are generally introduced at a large scale by public work departments, not by individuals. For example, roadside trees are often established and maintained by local governments. Thus, to introduce such GI, the public administration should take interest. Therefore, the implementation potential of this type of GI can be evaluated based on the situation of human society, mainly the top-down regulation such as that by the government. This administrative regulation is the second essential dimension for evaluating the implementation potential of GI. 


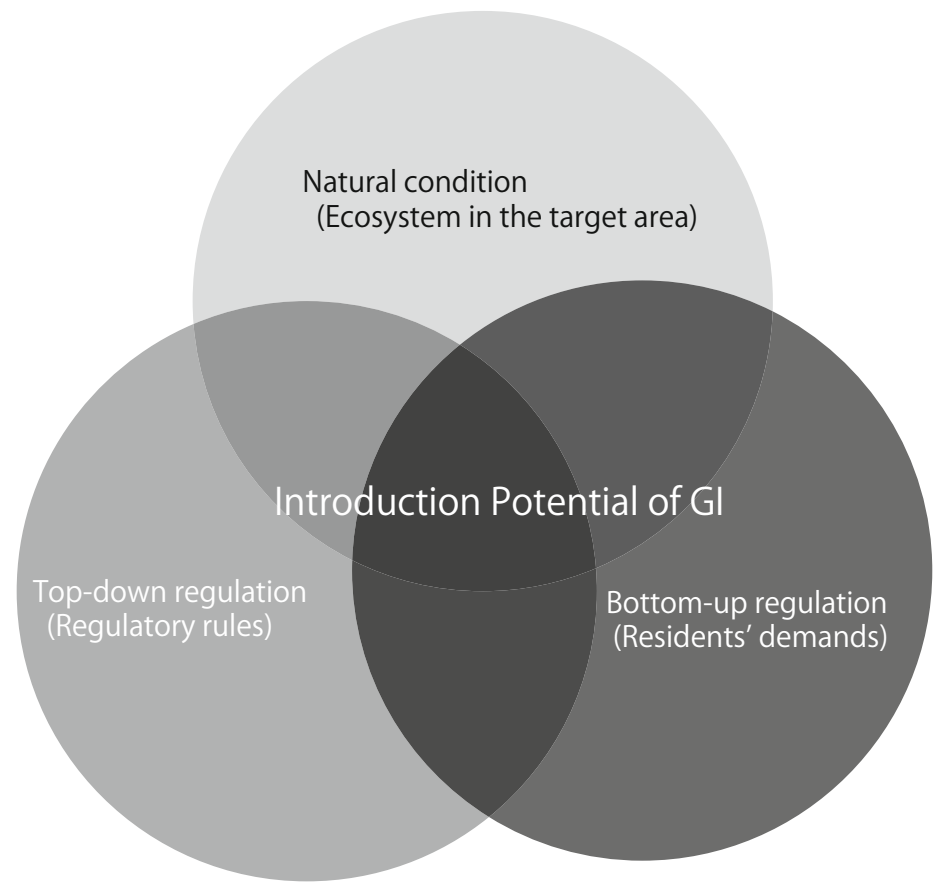

Fig. 5.2 Three essential dimensions to estimate the implementation potential for GI

Third is bottom-up regulation (Fig. 5.2). To decide the specific public work, public administrations should respect the will of the residents. Thus, to introduce GI in residential areas, the residents too should take interest in the GI. This demand/requirement, i.e., bottom-up regulation, is the third essential dimension for estimating the implementation potential of GI. Thus, the implementation potential of GI is based on three essential dimensions that are often related to each other (Fig. 5.2). We can clearly define and evaluate these aspects independently. Next, we discuss these three dimensions more in detail.

\subsubsection{Natural Condition}

The first dimension, i.e., the natural conditions, is the easiest dimension to perceive and evaluate because it is essentially the ecosystem existing in the target area. Thus, the expected benefits of the GI are almost the same as the existing ecosystem services. The aim of introduction of the GI should be to employ and/or enhance their existing ecosystem services in the target area. For example, the Ministry of Agriculture, Forestry and Fisheries, Japan, has adopted a GI-related policy to enhance the ecosystem services produced from agricultural areas using direct 
payment systems (MAFF web site https://www.maff.go.jp/j/nousin/kanri/tamen_ siharai.html, accessed on February 10, 2021). The Forestry Agency, Japan, has made efforts to promote GI with efforts to maintain forests (Maeda 2017). Both agricultural and forest ecosystems are already known to provide several ecosystem services (Matsuno et al. 2006; Natuhara 2013; Osawa et al. 2020a, b); hence, these GI strategies aim to use and maintain these existing ecosystem services. Therefore, if a decision maker plans to apply natural and seminatural ecosystem GI in a specific area, they must consider the local ecosystem and the type of ecosystem services that can be obtained in this target area as the basis of GI. This is a very simple condition. Additionally, the practitioner should focus on the benefits they expect from that GI. For example, a paddy field is an extremely useful GI because of its multiple functions besides food production: ecosystem services such as regulating service, cultural service, and supporting service (Natuhara 2013). However, the relative values of the services strongly depend on their local conditions. A previous study reported a trade-off relationship between the provisioning service and supporting service in a paddy field (Osawa et al. 2016). Further, the regulating service, in specific, flood prevention, strongly depends on the location (Osawa et al. 2020a). Therefore, to introduce a natural and seminatural ecosystem-based GI, practitioners should consider the types of the existing ecosystems and the services that can be extracted from them.

\subsubsection{Top-Down Regulation}

The second dimension, i.e., top-down regulation, refers to the social regulatory rules, such as laws, administrative programs, and related individual rights. We cannot consider any ecosystem as GI without considering such top-down regulation even when the focusing ecosystem has high potential. For example, a protected area such as a national park that is strongly regulated for any development work can be a potential GI (Benedict and McMahon 2006), but its uses are restricted according to the regulatory roles. In other words, within the protected area, the expected ecosystem services, i.e., benefits to humans, may be regulated. For example, it is difficult to receive any provisioning services from a closed zone in a protected area. The decision maker should not consider these unavailable ecosystem services in the focusing area as the benefit of GI. However, the regulatory roles could promote the application of the area as GI. For example, according to the Urban Park Act, Japan, urban green spaces are expected to provide the temperature reduction effects in summer (https://www.kantei.go.jp/jp/singi/tiiki/kokusentoc_ wg/hearing_s/150123siryou03_1.pdf, in Japanese, accessed on February 10, 2021). This type of ecosystem services is easy to use as the function of GI for urban green space (Matsunaga and Osawa 2021). Both the introduction advisability and expected ecosystem services are basically decided by the role of the human society. Therefore, one effective way to evaluate the implementation potential of GI is to review administrative documents. Administrative documents include laws, local 
codes, and administrative programs such as city development, environment, and water usage. One specific example of administrative document in the environment is the establishment of the biodiversity strategy by the national government and some local governments based on the recommendation by the Convention on Biological Diversity. Any mentions of both the protected area and ecosystem services expected from the current ecosystems in the document can be a key factor for introducing GI in the area. These documents provide us hints regarding the implementation potential of GI.

The top-down regulation is not only administrative but can also include individual rights such as property rights. To simplify, if a practitioner wants to apply GI for a given forest land, the permission of the landowners is essential. Of course, this type of regulation can exist for intact ecosystem. Such top-down regulations are essential for applying GI because almost of all land, sea, and rivers, i.e., ecosystems, are owned and/or managed by someone.

\subsubsection{Bottom-Up Regulation: Residential Demands and Requirements}

The third dimension is also a part of social regulation, but this arises from bottom-up regulation, i.e., the demand/requirements of local residents. If a government wants to introduce GI in an administrative area, they should first estimate and visualize the merits of the GI for residents because public works must be undertaken only if it has public benefits. Unfortunately, estimating the benefits of GI in detail is difficult because of the uncertainty of the multiple functions of GI, at least partly owing to the limited knowledge regarding them at present. Thus, residential acceptability, i.e., the appreciation and understanding of ecosystem functions and/or services, is one of the key factors determining the implementation potential of GI.

Residential appreciation and understanding of ecosystem function and/or services are difficult to estimate because they are qualitative factors. Recently, these qualitative factors were estimated quantitatively via interview and questionnaire surveys (Cheng et al. 2019). People who have interest and/or affinity toward ecosystem or natural environment may have a relatively high acceptability for the introduction of GI as a part of the ecological system.

\subsection{Evaluation of the Potential for Introduction of GI}

To summarize, the three essential dimensions of evaluating the implementation potential of GI are the natural condition, top-down, and bottom-up social regulations (Fig. 5.2). Notably, relative importance of three dimensions among GI types could differ (Fig. 5.3). For example, the natural ecosystem-based GI is strongly 

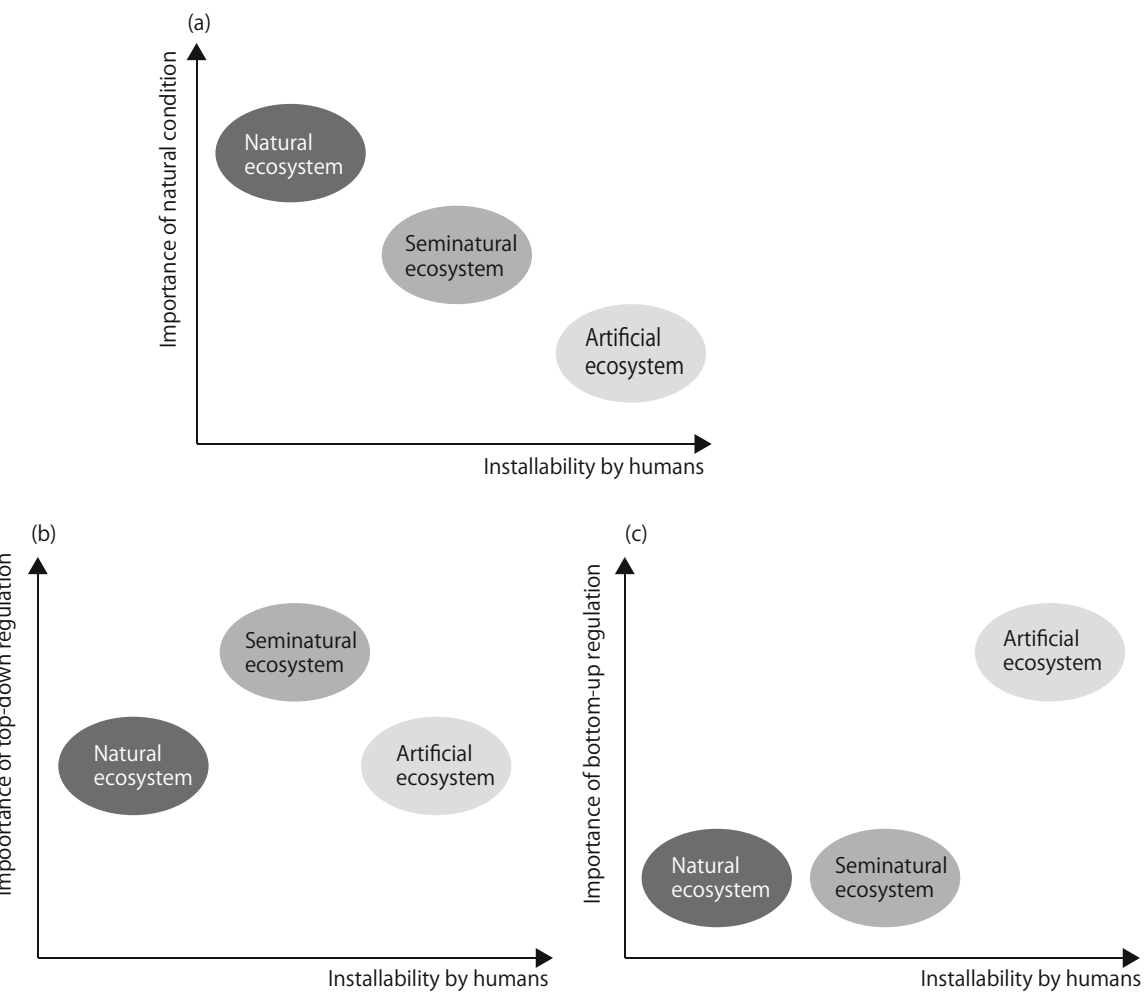

Fig. 5.3 Relative importance of three dimensions: (a) natural condition, (b) top-down regulation, and (c) bottom-up regulation for each GI type

Table 5.1 Relative importance of each dimension in each type of GI

\begin{tabular}{l|l|l|l}
\hline GI type & Natural condition & Top-down regulation & Bottom-up regulation \\
\hline Natural ecosystem & High & Moderate & Low \\
\hline Seminatural ecosystem & Moderate & High & Low \\
\hline Artificial ecosystem & Low & Moderate & High \\
\hline
\end{tabular}

regulated by the natural condition, i.e., the first dimension (Fig. 5.3a). A seminatural ecosystem-based GI is strongly regulated by top-down regulation, i.e., the second dimension (Fig. 5.3b). An artificial ecosystem is strongly regulated by bottom-up social regulation, i.e., the third dimension, but rarely regulated by the first dimension (Fig. 5.3a, c). A decision maker should consider all the three dimensions when introducing GI in the planning stage. Table 5.1 summarizes the relative importance of each dimension for each type of GI, which can be used by the practitioners as a checklist in the local planning of GI; at least the items marked "high" should be carefully considered to introduce GI suitably for the target area. 


\subsection{Conclusion and Perspective}

We classified the GI into three types on the basis of ecosystems and considered the basic concept for evaluating the implementation potential of each type of GI in three dimensions. Essentially the ubiquitous objects, i.e., ecosystems in our society, can function as GI, but there exists a large variety in such elements. Some types of GI can cover a wide area and provide several benefits, while others may exist locally and provide fewer benefits. GI is a comprehensive concept of the use of an ecosystem for the human society. Thus, the basic idea of GI itself is not new. However, the word "infrastructure" refers to the basic systems and services for human society that are managed by a country or an organization. Thus, the idea of GI may include the concept that the human society should use natural environment more systematically and effectively. Expanding the idea of GI is almost the same as establishing a society that is in harmony with nature. Estimating the implementation potential of GI is an important step to expand the GI for our society.

Acknowledgments This work was supported by the Environment Research and Technology Development Fund (4-1805) of the Ministry of the Environment, Japan, and partially supported by the JSPS KAKENHI Grant Number 20 K06096. Profs. F. Nakamura and N. Furuta provide us many useful suggestions.

\section{References}

Benedict MA, McMahon ET (2006) Green infrastructure. Island, Washington, DC

Chen WY (2015) The role of urban green infrastructure in offsetting carbon emissions in 35 major Chinese cities: a nationwide estimate. Cities 44:112-120

Cheng X, Van Damme S, Li L, Uyttenhove P (2019) Evaluation of cultural ecosystem services: a review of methods. Ecosyst Serv 37:100925

Cortinovis C, Geneletti D (2018) Ecosystem services in urban plans: what is there, and what is still needed for better decisions. Land Use Policy 70:298-312

Eggermont H, Balian E, Azevedo JMN et al (2015) Nature-based solutions: new influence for environmental management and research in Europe. GAIA Ecol Perspect Sci Soc 24:243-248

Ishimatsu K, Ito K, Mitani Y et al (2017) Use of rain gardens for stormwater management in urban design and planning. Landsc Ecol Eng 13:205-212. https://doi.org/10.1007/s11355-016-03093

Maeda S (2017) Green infrastructure: forestry and trends in securing new Funcing sources. Q J Public Policy Manag 2017:47-57. (in Japanese)

Martin TG, Watson JEM (2016) Intact ecosystems provide best defence against climate change. Nat Clim Chang 6:122-124. https://doi.org/10.1038/nclimate2918

Matsunaga K, Osawa T (2021) A method for evaluating temperature reduction effect in urban green space: case study in the Central Tokyo metropolitan. Jpn J Conserv Ecol. (in Japanese)

Matsuno Y, Nakamura K, Masumoto T et al (2006) Prospects for multifunctionality of paddy rice cultivation in Japan and other countries in monsoon Asia. Paddy Water Environ 4:189-197. https://doi.org/10.1007/s10333-006-0048-4

Nakamura F, Akasaka T, Ishiyama N et al (2019) Adaptation to climate change and conservation of biodiversity using green infrastructure. River Res Appl:1-13. https://doi.org/10.1002/rra.3576 
Natuhara Y (2013) Ecosystem services by paddy fields as substitutes of natural wetlands in Japan. Ecol Eng 56:97-106

Osawa T, Kohyama K, Mitsuhashi H (2016) Trade-off relationship between modern agriculture and biodiversity: heavy consolidation work has a long-term negative impact on plant species diversity. Land Use Policy 54. https://doi.org/10.1016/j.landusepol.2016.02.001

Osawa T, Nishida T, Oka T (2020a) High tolerance land use against flood disasters: how paddy fields as previously natural wetland inhibit the occurrence of floods. Ecol Indic 114:106306

Osawa T, Nishida T, Oka T (2020b) Paddy fields located in water storage zones could take over the wetland plant community. Sci Rep 10:1-8

Pearlmutter D, Calfapietra C, Samson R et al (2017) The urban forest: cultivating green infrastructure for people and the environment. Springer, Cham. https://doi.org/10.1007/9783-319-50280-9

Romano G, Dal Sasso P, Trisorio Liuzzi G, Gentile F (2015) Multi-criteria decision analysis for land suitability mapping in a rural area of Southern Italy. Land Use Policy 48:131-143. https:/ /doi.org/10.1016/j.landusepol.2015.05.013

Spanò M, Gentile F, Davies C, Lafortezza R (2017) The DPSIR framework in support of green infrastructure planning: a case study in Southern Italy. Land Use Policy 61:242-250. https:// doi.org/10.1016/j.landusepol.2016.10.051

Svarstad H, Petersen LK, Rothman D et al (2008) Discursive biases of the environmental research framework DPSIR. Land Use Policy 25:116-125. https://doi.org/10.1016/ j.landusepol.2007.03.005

Svensson J, Andersson J, Sandström P et al (2019) Landscape trajectory of natural boreal forest loss as an impediment to green infrastructure. Conserv Biol 33:152-163

Tzoulas K, Korpela K, Venn S et al (2007) Promoting ecosystem and human health in urban areas using green infrastructure: a literature review. Landsc Urban Plan 81:167-178

Zhang B, Li W, Xie G (2010) Ecosystem services research in China: progress and perspective. Ecol Econ 69:1389-1395

Open Access This chapter is licensed under the terms of the Creative Commons Attribution 4.0 International License (http://creativecommons.org/licenses/by/4.0/), which permits use, sharing, adaptation, distribution and reproduction in any medium or format, as long as you give appropriate credit to the original author(s) and the source, provide a link to the Creative Commons license and indicate if changes were made.

The images or other third party material in this chapter are included in the chapter's Creative Commons license, unless indicated otherwise in a credit line to the material. If material is not included in the chapter's Creative Commons license and your intended use is not permitted by statutory regulation or exceeds the permitted use, you will need to obtain permission directly from the copyright holder. 